\title{
Genotyping of pathogenic leptospira by Multiple Locus Variable-number Tandem Repeat Analysis (MLVA)
}

\author{
Vitalii Ukhovskyi ${ }^{\star 1}$, Taras Tsarenko ${ }^{3}$, Nataliia Vydayko ${ }^{2}$, Leonid Korniienko ${ }^{3}$ and \\ Igor Nebogatkin ${ }^{2}$
}

'Leptospirosis laboratory with museum of microorganisms, Institute of Veterinary Medicine of the National Academy of Agrarian Sciences of Ukraine, Kiev, Ukraine; ${ }^{2}$ State Institution Ukrainian Center for Diseases Control and Monitoring of the Ministry of Health of Ukraine, Kiev, Ukraine; ${ }^{3}$ Bila Tserkva National Agrarian University, Bila Tserkva, Ukraine

\section{Objective}

To introduce the method of molecular genotyping (MLVA) to determine the genotype of field isolates of leptospira.

\section{Introduction}

Leptospirosis (ictherohemoglobinuria, Leptospirosis biliousness) is a natural focal and zoonotic infectious disease dangerous for humans and farm animals. It is important to identify specific leptospira strains isolated from rodents or sick and suspicious animals by the serotype or genotype. In comparison with serotyping using micro agglutination test (MAT), molecular genotyping makes it possible to accurately identify a specific pathogen strain. The genetic classification now becomes more significant than the phenotypic classification.

\section{Methods}

Specific oligonucleotide primers, which flank fragments of the genome locus of pathogenic leptospira varies in terms of the number of tandem repeats VNTR-4, -7, -10 specific for L.interrogans, L.kirschneri, and L.borgpetersenii were used. The amplification products were detected using agar gel electrophoresis with the following identification of the fragment length with a molecular weight marker and comparison with the collection of VNTR profiles of the strains described in the literature.

\section{Results}

It was established that the method of leptospira molecular genotyping by determining the number of variable tandem repeats of a locus (VNTR-variable number tandem repeats analysis) is suitable for molecular epizootology studies in Ukraine. The advantages of the method are the simplicity of performance and availability for diagnostic and research laboratories in Ukraine compared to other pathogen genome sequencing based genotyping methods, in particular Multilocus sequence typing (MLST) or Multispacer Sequence Typing (MST), which require complex equipment and operating conditions. The reference strain of Leptospira M20 serotype Copengageni serogroup Icterohaemorrhagiae from the NAAS IVM collection of was studied and its VNTR profile was identified with the genotype of the strain Fiocruz L1-130 that is described in the literature as a serotype of Copengageni serogroup Icterohaemorrhagiae. The genotype of the leptospira field isolate obtained from a rat in Lviv Oblast of Ukraine was specified and its identity was established in the aforementioned genotype. The obtained data support the prospects of using MLVA genotyping method to study the distribution of different genotypes of leptospira. The research will continue to study the specificities of molecular epizootology of leptospirosis in Ukraine.

\section{Conclusions}

The method of leptospira molecular genotyping by multilocus analysis of the number of variable tandem repeats has been tested in the Leptospirosis Research Laboratory in collaboration with the Museum of Microorganisms at the National Academy of Sciences, the Ukraine Institute of Veterinary Medicine, the ELISA and PCR
Research Laboratory, and the Bila Tserkva National Agrarian University. The genotype of the reference strain has been correlated with its serological profile; identification of the genotype of the field isolate pathogenic leptospira has been completed. The tested method is planned to be implemented in surveillance and control over leptospirosis spreading in Ukraine, and aimed to help in development and improvement of leptospirosis vaccine formulations. Additionally, method of Multiple-Locus Variable number tandem repeat Analysis will be used for molecular epidemiology research in Ukraine.

\section{Keywords}

Leptospira; Genotyping; MLVA; VNTR

\section{Acknowledgments}

The authors would like to acknowledge the United States Department of Defense, Defense Threat Reduction Agency (DTRA), and Cooperative Biological Engagement Program (CBEP) for their support in the development and presentation of this abstract.

\section{References}

Salaün L, Mérien F, Gurianova S, Baranton G, Picardeau M. Application of multilocus variable-number tandem-repeat analysis for molecular typing of the agent of leptospirosis. J Clin Microbiol. 2006;44(11):3954-3962. doi:10.1128/JCM.00336-06.

Caimi K, Repetto SA, Varni V, Ruybal P. Infection, Genetics and Evolution Leptospira species molecular epidemiology in the genomic era. Infect Genet Evol. 2017;54(July):478-485. doi:10.1016/j. meegid.2017.08.013.

Ayral F, Zilber AL, Bicout DJ, Kodjo A, Artois M, Djelouadji Z. Distribution of leptospira interrogans by multispacer sequence typing in urban Norway rats (Rattus norvegicus): A survey in France in 2011-2013. PLoS One. 2015;10(10):1-14. doi:10.1371/journal. pone. 0139604 .

\section{*Vitalii Ukhovskyi \\ E-mail: uhovskiy@ukr.net}

